\title{
Trends of Modern Education Development in the European Educational Space
}

\author{
Svitlana Z. Romanyuk ${ }^{1}$, Ivan S. Rusnak ${ }^{2}$, Maryna S. Vasylyk ${ }^{3}$, Olena M. Novak ${ }^{2} \&$ Inna M. Shorobura ${ }^{2}$ \\ ${ }^{1}$ Yuriy Fedkovych Chernivtsi National University, Chernivtsi, Ukraine \\ ${ }^{2}$ Khmelnytsky Humanitarian Pedagogical Academy, Khmelnytsky, Ukraine \\ ${ }^{3}$ Vasyl Stefanyk Precarpathian National University, Ivano-Frankivsk, Ukraine \\ Correspondence: Svitlana Z. Romanyuk, Yuriy Fedkovych Chernivtsi National University, 14 Rivnenska str., \\ Chernivtsi, 58003, Ukraine.
}

Received: June 10, 2020

Accepted: August 3, 2020

Online Published: August 4, 2020

doi:10.5430/ijhe.v9n7p47

URL: https://doi.org/10.5430/ijhe.v9n7p47

\begin{abstract}
The article summarizes that the establishment and development of common language educational space of the EU were caused by an aggregated impact of external factors in the form of social, economic, and political processes within European integration as well as by intra-system factors. Both the institutional and legal base and the open method of coordination in the sphere of language education at the EU level create difficult intra-system and external ties, providing the integrity of the educational space. The creation of a common language educational space is based on conceptual frameworks determining the content of educational policy at European and national levels. Modern trends of higher education have been analysed through the multicultural aspect of society. The assumption about the appropriateness of continuous language training of students as the basis to form skills for intercultural communication has also been made. To check the credibility of results achieved during research and development works methods of mathematical statistics have been used. They included non-parametric methods of results comparison, which according to Kyveryalg are the most appropriate while professional analysis of pedagogical phenomena. It is explained by the fact that there is a limited number of quantity indicators obtained as a result of pedagogical studies (four levels of intercultural communication skills) in the science of pedagogy. The results proved the effectiveness of the developed methodology, which is based on the implementation of context-based learning techniques while learning a foreign language (English) by students.
\end{abstract}

Keywords: trends, European educational space, students, intercultural communication skills, foreign language training, teachers, context-based learning technologies, experiment

\section{Introduction}

The modern stage of educational development is characterized by the impact of globalization processes. In many cases, they identify changes happening in the educational policy: the emergence of new problems and tasks that demand the international cooperation; cooperation and competition manifestation in the process of educational policy realization; and internalization of language education. On the other hand, the globalization crisis and the crisis of existing international institutions contribute to the regionalization trend as a new format of countries cooperation for mutual formulation and promoting the interests on global sets (Bruckmann \& Carvalho, 2018). In parallel, an active formation of the system of preferential trade and economic agreements between countries are happening. These processes determine the choice of priority areas of the language educational policy and mechanisms of its formation. Under these circumstances, the peculiarities study of establishment and development of the language educational space of the European Union is regarded as a system resource for creation and effective internal organization of integration unions and their cooperation (Buyak, Tsidylo, Kozibroda \& Repskyi, 2019). The European Union has a unique experience in realization of integration processes, and it is one of the most successful examples of integration unions creation in the world.

The European Union is one of the main political and economic centers in the language world, which influences the work of international institutions, and the global political and economic conjuncture. The creation of a common language educational space in Europe is determined by political, social, and economic priorities of the community development, which are reflected in the goal settings, educational programs, and processes realization both inside the 
community and in other regions of the world (Barros, 2012). For Ukraine, which is a participant of the Bologna process and common EU programs, understanding of pull and system factors of these processes is a requirement for partnership and effective participation of the country in their realization and preservation of Ukrainian language educational system competitiveness in the world and European markets of educational services. Besides, the studies of trends in the development of the EU educational space have a historically pedagogical value because Ukraine is an integral part of the European space, and the Ukrainian educational system is a medium of common European educational values and traditions regardless of modern political fluctuations. The role of language education in the realization of cohesion policy is to integrate the youth into the labour market, increase competitiveness and investment appeal of regions. Thus, summing up the stated above, the main trend of language education is the formation of intercultural communication skills in the European Union.

Economic, social, and cultural changes happening in the modern world contribute to the increase of intercultural communication, enhance cooperation in the international educational projects, and increase professional contacts between representatives of different cultures. The stated above demands mastering professional competence by future specialists. The integral indicator of competence is a proficient level of a foreign language and rules of intercultural communication. Base on the stated, while learning a foreign language, the problem of students training for intercultural communication is one of the most urgent, and it is an important condition for their integration into a multicultural society.

In Ukraine, students training for cooperation with foreign partners, a personality integration into systems of global and national cultures, intellectual and communicative development of future specialists' personality has been reflected in the State educational standard of higher and professional education and Ukrainian law "About education" as an objective of education. The Declaration on the creation of the European higher education area by 2010 adopted within the Bologna Process directs towards the necessity to increase the level of foreign language teaching to ensure students readiness for the life and work in a multilingual world.

It should be stated that the educational process realized in high school in EU countries is always regulated by normative documents where demands to the professional training of future specialists are written. They include initiative, deep professional knowledge and skills, sociability, ability to use the experience flexibly, and continuous self-development. During the process of higher education receiving a student must master a set of necessary competences, which will contribute to the effective future work learning, thus, stimulating the development of professional motives (Beketova, Kuprina \& Petrikova, 2018; Mebuke, 2016; Wang et al., 2018).

Thus, the competences of a future specialist, which a student has to master by studying some academic disciplines in higher education institutions, are provided in the state standards of higher education. Obviously, the realization of the competence approach in the professional education will contribute to the training of a qualified, competitive on the labour market specialist capable to work effectively on specialty at the world standards level, who is ready to continuous professional growth, social and professional mobility (Baig, Ting-Toomey \& Dorjee, 2014; Byram, 2009; Carbaugh, 2007; Jackson, 2014; Mesidor \& Sly, 2016).

In the first place, the condition, content, and the structure of higher education are determined by the state of the pedagogical science and practice that have the scientific grounding of particular changes in this sphere. Under such conditions, the problem of forming intercultural competence that enables specialists to adapt to the existing conditions of professional work and integrate into the social and economic space of the EU has become particularly relevant.

Notions of intercultural competence are often related to such an extensive process as intercultural communication. Intercultural communication is a field that studies the interaction of individuals with various samples of historically derived behaviour, the cooperation of parties with different experiences. It is also such a type of communication where a sender and a receiver belong to different cultures. Nowadays, researchers conduct a general analysis of interconnection between communication and culture, emphasizing that several events are taking place during this process, namely:

a) a shift from one-culture focus to bi-cultural comparison;

b) a concept of culture can go from the macro-level to the micro-level;

c) marked connection of culture with the communicative process;

d) determined role of culture in influencing human behaviour (Slyusarenko \& Soter, 2016).

Thus, the basis of intercultural communication is the idea of cooperation of basic components of culture: values, 
norms, settings, language codes, and concepts. Intercultural communication is regarded from several points of view in psychological and pedagogical literature. In some studies, intercultural communication is mainly considered as interaction of cultures (Smelikova, 2015; Smorochynska, 2011; Soter, 2017). In these works, intercultural communication is studied as the process of direct interaction of cultures under different national stereotypes of thinking and behaviour what has a great impact on communicators relations (Kostiuk, 2018a; 2018b; Soter, 2016a; 2016b).

In other researches, intercultural communication is characterized as the interaction of culture representatives (Halytska, 2014; Kostiuk, 2015; Thome Williams, 2016). Some researchers emphasize the necessity of "adequate mutual understanding," focusing on communication effectiveness (Afanasieva \& Oleksenko, 2018; Bakhov, 2014; Furstenberg, 2010; Motsar, 2015). The researchers' views are limited to the fact that some of them pay special attention to a communicative component of the intercultural communication process, emphasizing communication of people and information exchange, and others - cultural cooperation when intercultural communication is understood as the interaction of representatives of a different culture that is just represented by different language systems.

The pedagogical interpretation of intercultural communication in European higher education institutions (HEI) involves developing the skill to understand common and different things in the native and foreign cultures for improving the features of an inter-culture-oriented person. Intercultural communication is characterized by the fact that when meeting representatives of different cultures, each of them acts in accordance with his/her cultural norms. All views on the essence of intercultural communication converge in one semantic center, namely in an idea of cooperation between communicators who belong to different language and cultural communities.

Now the problem of forming a skill to establish intercultural foreign language communication is in the focus of the European pedagogical society due to the increasing necessity to provide deep and developed skills in the sphere of foreign languages to students of HEI. In addition, they also need to develop their personal qualities, which promote full participation in a so-called dialogue among cultures. Nowadays nobody doubts that even if you know perfectly a language but do not understand the culture of its native speakers, it will not result in a mutual understanding of the parties. Thus, it is important to both learn a foreign language and culture of the country, a language of which is learned.

According to the stated above, within a new educational paradigm, a task to reconsider the system of specialists training in the process of a secondary language personality formation is being set. Foreign language teaching must be done based on the basic principles of intercultural communication, which will contribute to the formation of such communication skills.

Intercultural communication is a set of specific cooperation processes of people who belong to different cultures and languages. It is happening between cooperation partners who belong to different cultures and take the foreign nature of the interlocutor. The development of intercultural communication problems strengthens the national security of each country-member of the EU in terms of international relations harmonization, peace-making, and consensus reaching between peoples. The recognition and understanding of different cultures result in cooperation, interdependency, and interchange (for example, of students or educational technologies). It also leads to open opportunities for cooperation in the sphere of music, art, and science. The role of such activities is obvious due to the emergence of a possibility to engage students in cultural values of different countries; formation of tolerant consciousness and the ability to take part in the direct dialogue of cultures; the emergence of a desire to overcome difficulties related to the clash of different cultures. It is necessary to mention that with regard to tackling challenges of intercultural communication, nowadays, a large number of scientific researchers are being conducted (Joe, 2010; Lalima \& Dangwal, 2017; Noble, Vangehuchten \& Parys, 2011; Piller, 2017; Samovar, Porter, McDaniel \& Sexton, 2010).

Lately, one of the objectives of teaching foreign languages is mastering the language at the level sufficient for a student to take part in international communication in the language that is being studied. It means that it is necessary to know all types of language activities enough to have a direct dialogue with representatives of countries that are being studied (Haka, Borch, Jensen \& Leppin, 2011).

Now, a foreign language is not regarded as just a system of certain grammatical rules and a set of lexical units necessary for foreign language understanding. It is a component of the common culture of a personality through which s/he can become a part of the world culture. The cultural barrier, including a language one, can become a real factor that interferes with a mutual understanding of communication participants. In the process of foreign language teaching, culture-oriented elements are combined with language phenomena resulting in the combination of learning both a language and cultural knowledge as well as in the formation of the possibility to understand the mentality of 
other language native speakers.

Possessing skills of intercultural communication is essential for students of HEI, and their future professional work, which engages extensive intercultural contacts. However, the studies conducted by us demonstrated that modern Ukrainian students do not have deep knowledge and enough skills of intercultural communication, do not always understand their own and other people's national and cultural peculiarities and they are not ready to build relations with representatives of other cultures based on tolerance and peacefulness.

In the educational process of HEI, they do not pay enough attention to promoting a tolerant and respectful attitude to other cultures among students, while the success of functioning intercultural foreign language communication is determined by the formation level of intercultural foreign communicative competence as the aim-result of foreign language education in HEI. The facts prove the appropriateness of improving the existing system of student language training in intercultural communication. They also highlight the necessity to organize foreign language teaching. For that purpose, an attempt to implement technologies of context-based learning to develop skills in intercultural communication of future specialists while studying in HEI has been made.

Summing up, we note that the dynamic integration of the world space in terms of its openness increasingly shows the current trends of globalization, unification, informatization, and standardization of the quality of education. An open society required an open educational space and made it real, which means a stable set of educational ties between states and within them, thus posing the problem for a student of entering it as a social actor who explores and uses its potential.

Globalization of education, which is stimulated by a high level of development of the world community, dynamic socio-economic, political and cultural changes, sustainable development of educational systems, leads to a single educational space, mostly European, requiring new strategic guidelines for education in modern and future world.

The unification of education, in particular consolidation of the "European dimension" in higher education, concerns its goals, content, technology, and the result achieved for the individual and society. The idea of continuity of education from preschool, general secondary education, vocational secondary education, and higher education to long-term adult education (life-long education; permanent education) is implemented in a new structure of multilevel higher education (three levels - undergraduate, graduate postgraduate), use of various forms of education, expansion of the number of specialties, the use of credit, accumulative multi-point system of knowledge assessment, a significant increase in the proportion of time for independent work of pupils and students, their implementation of socially and practice-oriented projects and, finally, the right of pupils/students to choose teachers.

These trends directly relate to the informatization of education, the use of the richest information resources that significantly change the role of knowledge as the main driver of economic, technical, cultural and spiritual development of man and humanity. This is where the search for a new mission of higher (university) education results from in the context of the transition of humanity to a model of sustainable development. Universities are becoming the epicenters of regional education programming (in economic, social, cultural, environmental senses); assimilate a new innovative-entrepreneurial model, which turns into a research-educational-production complex with an academic core and interdisciplinary project-oriented periphery, consisting of network innovative high-tech entities and small enterprises that actively work with the orders of regional government, business, production and society as a whole.

\section{Materials and Methods of Research}

To check the credibility of results achieved during research and experimental work, methods of mathematical statistics have been used. They included non-parametric methods of results comparison, which according to Kyveryalg (1980) are the most appropriate while professional analysis of pedagogical phenomena. It is explained by the fact that there is a limited number of quantity indicators obtained as a result of pedagogical studies (four levels of intercultural communication skills) in the science of pedagogy (Kyveryalg, 1980).

For each group of results, we hypothesized (a null-hypothesis $H_{0}$ ) that results in experimental and control groups did not have any differences after the experiment. To check the validity of a null-hypothesis $\left(H_{0)}\right.$ about a lack of statistically significant differences between obtained indicators, a statistical criterion $\chi^{2}$ (Pearson's criterion) of experimental results in control and experimental groups was calculated.

As the number of students in control and experimental groups were not equal (120 and 118 people accordingly) due to natural causes, relative distribution of frequencies, the sum of which is always $100 \%$, was used while calculating criterion $\chi^{2}$ under the formula (Kyveryalg, 1980): 


$$
\chi^{2}=\sum_{i=1}^{n}\left[\left(f^{\prime} e i-f^{\prime} k i\right)^{2} / f^{\prime} k i\right]
$$

where $\chi^{2}$ - Pearson's criterion;

$f^{\prime} e i$ - relative frequency of $e$-value (experimental) on " $i$ " interval;

$f^{\prime} k i$ - relative frequency of $k$-value (control) on " $i$ " interval.

Relative frequency $f^{\prime} i$ - on " $i$ " interval is calculated as follows:

$$
f^{\prime} i=F i / \sum_{i=1}^{n}[F i]^{*} 100
$$

where $F i$ - frequency of value manifestation ( $e$-experimental, $k$ - control) on " $i$ " interval, " $i$ " takes the value from 1 to $n$ ( $n$ - quantity of intervals).

\section{Results}

The changes happening at global, regional, and local levels influence the development of integration processes in the sphere of language education in the EU. The specificity of the last decades lies in abandoning a former way of world community organization and weakening the country's sovereignty. National countries face new functional problems, which need international cooperation; they have to share the international stage with various global agents and enter supranational and regional organizations. The global economic culture is also created under the pressure of internalization, globalization, and integration processes, which determine almost all economic activities of the developed countries. In the world economy, these processes are interdependent and are intertwined, but they have their own characteristic features. In the end of the XX century, the change of economic development paradigm of industrially developed countries happened. It resulted in the emergence of a new economy, which is based on knowledge and artificial intellectual areas, change from goods production to service production, and globalization of economic and social processes. The knowledge economy and globalization, which wipes out national borders of competition, nominated the country's human resources and intellectual and educational potential as a key resource of economic growth, provision of competitiveness and well-being of the country. In this context, the problem of forming skills of intercultural communication is particularly urgent. Under globalization terms, the differences in levels of population's language education between countries have a crucial impact on the perpetuation of inequality on a global scale.

The society's need in intercultural communication stimulates purposeful foreign language communicative development of a personality and means that students have to master norms and rules of cooperation with representatives of other linguistic, social, and cultural communities, which is social predestination of forming a graduate's personality of any educational establishment.

Besides, we want to mention than the analysis of scientific literature enables us to determine that the main disadvantages of the system of language education management in the EU included the keeping of centralized and ineffective regulation and financing, extra bureaucracy in the process of decision-making as well as non-transparent reporting. Traditionally, European education was regarded as one of the most prestigious in the world. However, in recent years, data of international comparative studies, national reports on the state of the educational systems, including dropout rates from schools and HEI, have shown a decline in the quality of education and its competitiveness. Modernization and reforming of the educational system are considered as a means to overcome this situation. The main areas of reforms are deregulation, decentralization, the increase of educational establishments' autonomy; strengthen of the system's openness with active participation and control on the part of the society.

Decentralization of the language education management provides the opportunity for greater and more effective financing of higher schools, creates a more favourable innovative educational environment, and contributes to the creation of local student communities. Deregulation of education occurs in the form of privatization and institutional autonomy and is more effective from the social and economic point of view. The results of comparative studies PISA that show the increase of achievement levels in all social classes and the effectiveness of educational systems are regarded as proof of the information stated above. Nevertheless, deregulation can be a catalyst for social inequality. Reporting of HEI, strengthening of external assessments of results, and provision of their transparency, engaging parents and representatives of society in the process of self-management can help avoid it. 
International processes influence the educational language policy of European countries greatly. This trend is expressed as follows: formation of educational language policy is based on results of international studies; national legislation and the state consider international agreements (for example, GATS) in their practice; countries-members of the EU participate in the community program "Education and training"; countries participate in international programs of cooperation and partnership.

The analysis of scientific literature confirmed our assumption about the necessity to ensure the continuity of the process of forming intercultural communication skills among future specialists during the entire period of study in HEI. The described process must be dynamic and be modelled with the help of a foreign language environment. Nevertheless, such systematic nature will determine the mainstreaming of students' motivation to master the skills of intercultural communication.

The effectiveness of the development of foreign language intercultural competence, one component of which is communication skills, among students is determined by adequacy and the motivation strength as well as by implementation of modern methods of foreign language learning and professional content of courses. Thus, to our mind, the process of enriching students' intercultural communication skills should be organized with a number of optimization conditions, including:

- reliance on a competence approach in students' foreign languages learning;

- ensuring the implementation of the learning context;

- taking into account the provisions of the activity approach: to ensure the participation of students in scientific conferences, seminars, meetings, and discussions with foreign specialists (who are native speakers of the language being learned), in research activities, in the practical implementation of innovative professional projects;

- creation of a free, creative, and democratic atmosphere in class;

- implementation of active, in particular problematic, teaching methods: business and role play, project-based learning, etc.;

- the use of modern forms and methods of foreign languages teaching: communicative-oriented, intensive, and computer-based learning;

- the revitalization of students' independence based on ensuring the competitive character of educational activity.

Thus, for example, while organizing training of students who became participants of experimental groups, the professional interest in mastering the skills of intercultural communication was stimulated by implementing the principle of the adequacy of educational, cognitive, and professional activities. For this purpose, we used methods and forms of holding classes, which imitated or reproduced social and psychological peculiarities of future professional activity. The pedagogical concept of context-based learning offers us a solution to the problem. Its essence is to obtain the status of knowledge as a conscious imprint of reality. From the outset, information must be "tried" to action and assimilated in its context. It is necessary that each concept or regulation introduced by a teacher rebuilds the structure of the previous experience and that its content connections with the situations of future professional implementation could be seen.

To achieve the goal, the main methods of forming students' intercultural communication skills based on technologies of context-oriented learning are determined: searching method, which demands from the students to make their own decisions; heuristic method, which involves the organization of search and creative activity based on the theory of element-wise learning; the method of incremental formation of mental actions and concepts (implementation of provisions stated in the theory of incremental learning), method of information resource (orientation of students in the information choice), coaching method (cooperation between a teacher and a student).

\section{Discussion}

To determine the dynamics of formation levels of students' intercultural communication skills, both at the beginning and after the experiment, we tested students in control and experimental groups by using developed test tasks. In addition, we conducted a comparative analysis of the distribution of the relative quantity of students by the levels of their readiness. Here are examples of such tasks.

\subsection{2-Year Students}

Select the correct option to fill in the missing words and translate the sentences.

The (1) ... slow rotation speed of the sun gives a revealing and subtle clue to the mystery of the origin of the planets. The sun (2) ... to be rotating as slowly as it actually does. Instead of spinning round once in about 26 days, as in fact 
it does, our expectation would be that it should rotate in as little as a few hours. You might be tempted to think that the calculations must be (3) ... But we can see that (4) ..., because many stars do in rotate around in a few hours, just as the calculations show they should.

(Fred Hoyle: The Nature of the Universe)

1 a) amazingly $\quad$ b) exceptionally $\quad$ c) extremely
2 a) simply has no business
b) ought not, in principle
c) would not be expected

3 a) inaccurate b) wildly wrong c) erroneous

4 a) this is not the case b) things are not too bad c) the figures are not wholly incorrect.

\subsection{3-Year Students}

Define the content of the sentences given below (positive or negative). Create new words with -ible, -able by using prefixes. Put them in the sentences, taking into account their contextual meaning. Translate the sentences.

Prefixes: non-, not, un-, in-, ir-.

Words: obtainable, deductible, acceptable, beatable, inflammable, edible, laudible, changeable, available, debatable, eligible, transportable, soluble, regrettable, workable, audible, comparable, questionable.

Sentences: 1 . The outlook is...

2. The committee has come up with what it hopes a ... solution.

3. Beware: Highly ...!

4. Imported oriental rugs and carpets at ... price.

5. All bills must be paid in local currency or by traveller's cheque. No other form of payment is ...

6 . The White House spokesman regretted that he was not ... for comment.

7. For foreign nationals working in the country, tax will be ... at source.

8. All persons over the age of 65 are ... for the senior Citizens' Railcard.

\subsection{4-Year Students}

Revise peculiarities of newspaper headings translation and translate them into Ukrainian.

1. A Taste of India.

2. Manwatching (on human behaviour - gesture and movement)

3. Heineken - Refreshes the parts other beers cannot reach

4. Johnny Walker - Born 1820, and still going strong (Johnny Walker whisky)

5. The Heart of the Dragon

6. The Ascent of Man (the development of the human race since prehistoric times)

7. Take the Money and Run

\section{CANADA - THE BIG COUNTRY FOR BIG VALUE HOLIDAYS}

\section{(Tourism Division of the Canadian High Commission)}

\subsection{5-Year Students}

Translate colloquial phrases in italics into Ukrainian. What grammatical, lexical, and stylistic peculiarities of translation of colloquial units?

1. A girl I know, who prided herself on her long slender thighs, gave up short dresses for ever after an assistant at a department store told her: 'The trouble is, Madam, you've got low knees.' (The Sunday Times)

2. Tito has shown even in old age the capacity to learn and the w: to change with the times - but not too hastily or fundamental! It is small wonder that this extraordinary man, who has lived through enough experience for several full lives, should have become a legend in his own lifetime. (Phyllis Auty: Tito: A Biography)

3. The Indian heart of hospitality is as a rule almost limitless, but Indian small talk is the smallest in the world. Party conversation a formal middle-class reception has a strange period charm, $s<$ faithfully does it parody the dafter conventions of the English scene. (James Cameron: An Indian Summer). 
By using the method of statistical analysis (through the calculation of linear correlation coefficients), a functional relationship between the degree of levels development of intercultural communication skills among students and the system of forming foreign language knowledge of future specialists has been identified. After the experiment, the students of control and experimental groups performed creative test tasks and revealed different levels of students' intercultural communication skills formation.

For greater salience in presenting results of levels formation of students' intercultural communication skills in control and experimental groups after conducting the forming experiment are shown in Figure 1.

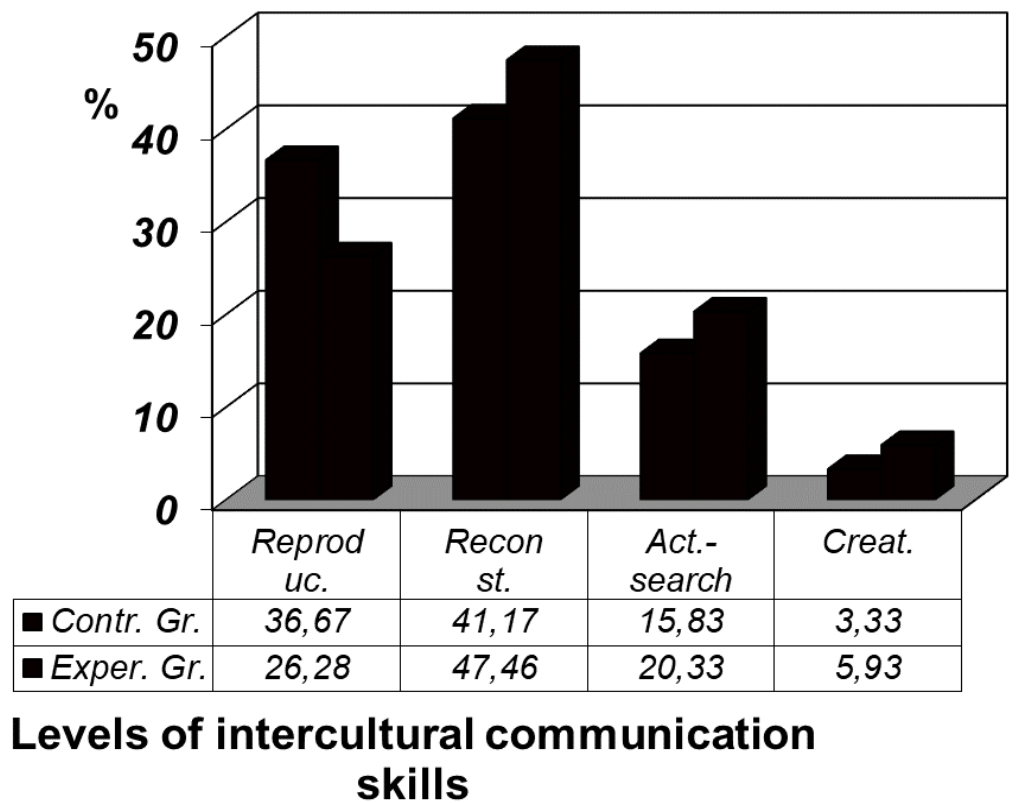

Figure 1. The dynamics of formation levels of students' intercultural communication skills in control and experimental groups after the experiment

Thus, at the reproductive level of students' intercultural communication skills formation, 44 students (36.67\%) were in control groups, while experimental groups counted 31 students $(26.28 \%)$. The number of students with a reconstructive level of intercultural communication skills formation in experimental groups is greater than in control groups - $56(47.46 \%)$ versus $53(41.17 \%) .19$ students $(15.83 \%)$ of the control group reached the active search level, while in experimental groups, this indicator was 24 students $(20.33 \%)$. There is also a difference in the indicators of the creative level of intercultural communication skills formation between students of control and experimental groups. At the creative level of readiness, there were 7 students, which is $5.93 \%$ in experimental groups, in control groups -4 students, $3.33 \%$. Thus, the formation level of students' intercultural communication skills in experimental groups was higher than in control ones.

Table 1 presents the results of formation levels of students' intercultural communication skills in experimental groups at the beginning and after the forming experiment.

Table 1. The dynamics of formation levels of students' intercultural communication skills in experimental groups at the beginning and after the forming experiment

\begin{tabular}{llllll}
\hline \multirow{2}{*}{$\mathrm{N}$} & $\begin{array}{c}\text { Levels of intercultural } \\
\text { communication skills }\end{array}$ & \multicolumn{2}{c}{$\begin{array}{c}\text { Experimental groups at the beginning } \\
\text { of the forming experiment }\end{array}$} & \multicolumn{2}{c}{$\begin{array}{c}\text { Experimental groups in the } \\
\text { end of the forming } \\
\text { experiment }\end{array}$} \\
\cline { 3 - 6 } & \multicolumn{2}{c}{ Abs. } & \multicolumn{2}{c}{ Abs. } & $\%$ \\
\hline 1 & Reproductive & 54 & 45.76 & 31 & 26.28 \\
2 & Reconstructive & 44 & 37.29 & 56 & 47.46 \\
3 & Active search & 17 & 14.4 & 24 & 20.33 \\
4 & Creative & 3 & 2.55 & 7 & 5.93 \\
Total number & 118 & 100 & 118 & 100 \\
\hline
\end{tabular}


In experimental groups, the number of students who reached the creative level of intercultural communication skills formation increased more than 2.3 times at the beginning and after the forming experiment (from $2.55 \%$ to 5.93\% almost by $3.5 \%$ ). At the same time, the number of students with a reconstructive level increased by 1.27 times (from $37.29 \%$ to $47.46 \%$ ), i.e. by $10 \%$. There is a noticeable increase in students who have an active search level -1.41 times (from $14.4 \%$ to $20.33 \%$ ), which is $5 \%$. Besides, the study found a decrease in the number of students with the reproductive level of readiness by almost 1.75 times (from $45.76 \%$ to $26.28 \%$ ). The decrease in this indicator is about $19.5 \%$.

For better clarity, the changes in the formation levels of intercultural communication skills in experimental groups at the beginning and after forming experiments are presented in Figure 2.

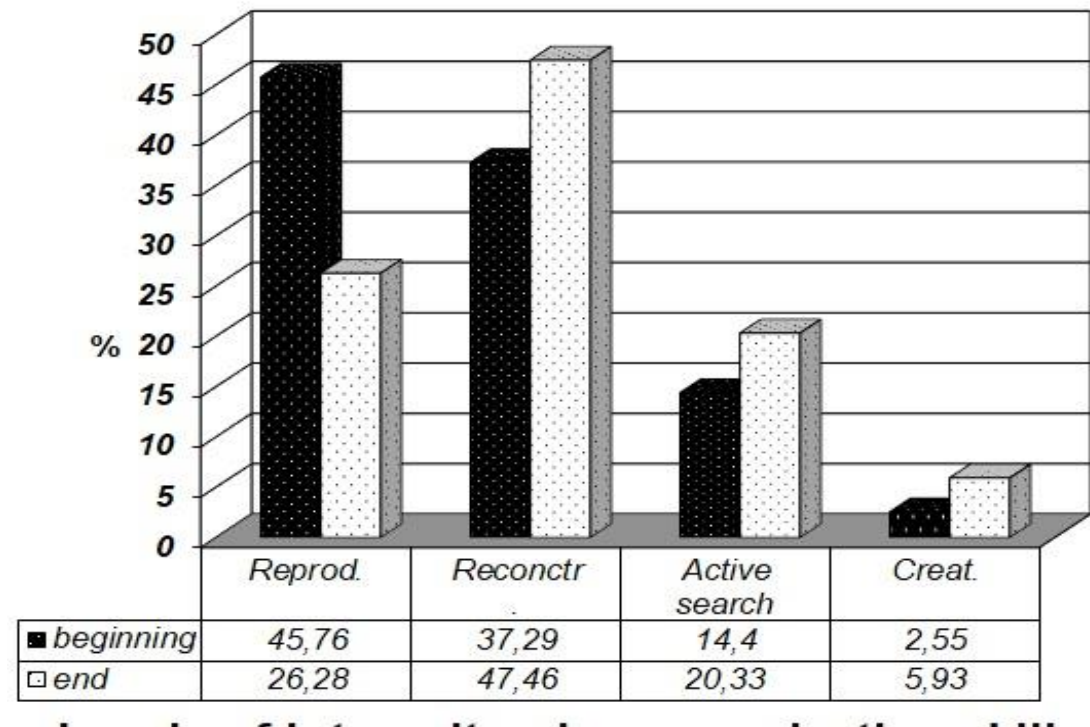

\section{Levels of intercultural communication skills}

Figure 2. The dynamics of levels of students' intercultural communication skills in experimental groups at the beginning and after the forming experiment

To check a lack of any discrepancies of the received data, let calculate $\chi^{2}$-criterion. To check a null-hypothesis $\left(H_{0}\right)$ on the absence of significant differences between the obtained indicators of the formation levels of students' intercultural communication skills in experimental and control groups after the experiment, we use the statistical criterion $\chi^{2}$ (Pearson's criterion) (Table 2).

Table 2. The change of levels of students' intercultural communication skills taking into account measurements of Pearson's criterion

\begin{tabular}{llllllll}
\hline $\begin{array}{l}\text { N of the } \\
\text { interval }\end{array}$ & $\begin{array}{c}\text { Frequency } \\
F e\end{array}$ & $\begin{array}{c}\text { Frequency } \\
F k\end{array}$ & $\begin{array}{c}\text { Relative } \\
\text { frequency } \\
f^{\prime} e, \%\end{array}$ & $\begin{array}{c}\text { Relative } \\
\text { frequency } \\
f^{\prime} k, \%\end{array}$ & $\begin{array}{l}\left(f^{\prime} e-f^{\prime} k\right) \\
\left(f^{\prime} e-f^{\prime} k\right)^{2}\end{array}$ & $\left(f^{\prime} e-f^{\prime} k\right)^{2} / f^{\prime} k$ \\
\hline 1 & 31 & 44 & 26.28 & 36.67 & -10.39 & 107.95 & 2.94 \\
2 & 56 & 53 & 47.46 & 41.17 & 6.29 & 39.56 & 0.96 \\
3 & 24 & 19 & 20.33 & 15.83 & 4.5 & 20.25 & 1.26 \\
4 & 7 & 4 & 5.93 & 3.33 & 2.6 & 6.76 & 2.03 \\
& $\Sigma \mathrm{Fe}=118$ & $\Sigma \mathrm{Fk}=120$ & $100 \%$ & $100 \%$ & & & $\chi^{2} \mathrm{emp}=7.19$ \\
\hline
\end{tabular}

$\chi^{2}$ calculation:

$$
\begin{gathered}
\chi^{2} \text { emp. }=(31 / 118 * 100-44 / 120 * 100)^{2} /(44 / 120)+(56 / 118 * 100-53 / 120 * 100)^{2 /}(53 / 120)+ \\
(24 / 118 * 100-19 / 120 * 100)^{2} /(19 / 120)+(7 / 118 * 100-4 / 120 * 100)^{2} /(4 / 120)=2,94+0,96+1,26+2,03=7,19 .
\end{gathered}
$$

For the freedom degree $3(n-1=3)$ (Kyveryalg, 1980), $\chi^{2}$ crit. $=7.81$, i.e. determined criterion $\chi^{2} e m p .<\chi^{2}$ crit. 
The null-hypothesis $\left(H_{0}\right)$ on the absence of differences between readiness levels in control and experimental groups is accepted and is regarded as a true one.

The number of intervals is $n=4$ (levels of students' intercultural communication skills); so, the number of freedom degrees becomes $n-1-3$. Based on the table of $\chi^{2}$ - criterion (Kyveryalg, 1980), we identify that $\chi^{2}$ that matches the 3 (third) level of freedom is equal to 7.81 at $95 \%$ level of probability. $\chi^{2} e m p .=7.19$ that we have found during the calculations is lower than 7.81, i.e. $\chi^{2}$ emp. $<\chi^{2}$ crit. Thus, calculation of $\chi^{2}$ - criterion demonstrated the correctness of the absent null-hypothesis $\left(H_{0}\right)$, and we can declare the absence of significant differences between the levels determination of students' intercultural skills in experimental groups at the beginning and after our experiment, i.e. conducted studies are reliable.

\section{Conclusions}

The conducted research has shown that the formation and development of the common language space in the EU are due to the comprehensive influence of external (in relation to the object of study) factors in the form of social, economic, and political processes within European integration, as well as intra-systemic factors. The institutional and legal framework and the open method of coordination in the field of language education at the EU level create complex internal and external connections, ensuring the integrity of the educational space. The construction of the common language educational space is based on the conceptual activities that define the content of education policy at the European and national levels.

In the current realities of international relations, for effective international cooperation and interaction, the formation of students' intercultural communication skills is an indispensable condition for the educational process. Intercultural education and training aim to prepare people for the conflict-free coexistence and cooperation of representatives of different cultures. The results of the research and experimental work confirmed the hypothesis on the connection existence between the values of control and experimental samplings. In addition, they showed a positive dynamics of the growth of the formation levels of students' intercultural communication skills, with the effectiveness of the results proved by statistical data, which confirm the hypothesis, adequacy, and effectiveness of the proposed methods of common skills formation. There were 44 students (36.67\%) at the reproductive level of students' intercultural communication skills formation in control groups, while the number of students in experimental groups was 31 people $(26.28 \%)$. The number of students who have a reconstructive level of intercultural communication skills development in experimental groups is greater than in control groups - $56(47.46 \%)$ versus $53(41.17 \%)$. Nineteen students $(15.83 \%)$ of the control group reached the active search level; while in experimental groups, this indicator was 24 students $(20.33 \%)$. There is also a difference in the indicators of the creative level of intercultural communication skills formation between students of control and experimental groups. At the creative level of readiness, there were seven students, which is $5.93 \%$ in experimental groups; and there were four students, $3.33 \%$ in control groups. Thus, the formation level of students' intercultural communication skills in experimental groups was higher than that in control groups.

\section{Research Perspectives}

The conducted research does not exhaust all aspects of the stated problem. The subject of further study may be the development of theoretical and practical provisions for the intercultural communication skills formation in HEI, a deeper study of psychological, pedagogical, and technical aspects of the development and implementation of context-based and blended learning technologies in the educational process.

\section{References}

Afanasieva, L., \& Oleksenko, R. (2018). Actual intercultural practices as an indicator of the interaction of cultural groups and communities of a polyethnic city. Visnyk of the Lviv University Philosophical Political studies, 18, 40-47.

Baig, N., Ting-Toomey, S., \& Dorjee, T. (2014). Intergenerational narratives on face: A South Asian Indian American perspective. Journal of International and Intercultural Communication, 7(2), 127-147. https://doi.org/10.1080/17513057.2014.898362

Bakhov, I. S. (2014). Dialogue of cultures in multicultural education. World Applied Sciences Journal, 29(1), 106-109.

Barros, R. (2012). From lifelong education to lifelong learning. Discussion of some effects of today's neoliberal policies. European Journal for Research on the Education and Learning of Adults, 3(2), 119-134. https://doi.org/10.3384/rela.2000-7426.rela0071 
Beketova, A. P., Kuprina, T. V., \& Petrikova, A. (2018). Development of students' intercultural communicative tolerance in the university multilingual educational environment. The Education and Science Journal, 20(2), 108-124. https://doi.org/10.17853/1994-5639-2018-2-108-124

Bruckmann, S. \& Carvalho, T. (2018). Understanding change in higher education: An archetypal approach. Higher Education, 76(4), 629-647. https://doi.org/10.1007/s10734-018-0229-2

Buyak, B., Tsidylo, I., Kozibroda, S. \& Repskyi, V. (2019). Ontological model of representation of university resources. Retrieved from http://ceur-ws.org/Vol-2393/paper_228.pdf

Byram, M. (2009). The intercultural speaker and the pedagogy of foreign language education. D. Deardorff (Ed.), The SAGE Handbook of Intercultural Competence, 321-332. Thousand Oaks, CA: SAGE Publications Inc.

Carbaugh, D. (2007). Cultural discourse analysis: Five communication practices and intercultural encounters. Journal of Intercultural Communication Research, 36(3), 167-182. https://doi.org/10.1080/17475750701737090

Furstenberg, G. A. (2010). A dynamic, web-based methodology for developing intercultural understanding. Proceedings of the 3rd international conference on intercultural collaboration ICIC, 10, 49-58. New York: Association for Computing Machinery. https://doi.org/10.1145/1841853.1841861

Haka, M., Borch, D. F., Jensen, C., \& Leppin, A. (2011). Should I stay or should I go? Motivational profiles of Danish seafaring officers and non-officers. International Maritime Health, 62(1), 20-30.

Halytska, M. M. (2014). Intercultural communication and itssignificance for professional activities of future specialists. Educological Discourse, 2(6), 23-32.

Jackson, J. (2014). Introducing language and intercultural communication. New York: Routledge. https://doi.org/10.4324/9781315848938

Joe, J. O. (2010). Cross-cultural communication issues on board. Proceedings of International Maritime English Conference-IMEC 22, 248-261. Alexandria, Egypt: Multimedia Centre AASTMT.

Kostiuk, S. (2015). Intercultural communication as a basis for learning a foreign language. In A. G. Gudmanyan, O. G. Shostak, \& O. V. Kovtun (Eds.), Ways to overcome language and communication barriers: Methods of teaching humanities to students of non-language specialties, 75-82. Kyiv, Ukraine: Talcom.

Kostiuk, S. (2018a). Methods of intercultural competencies development during the Ukrainian language training as a foreign. Social Education Project of Improving Knowledge in Economics, 19, 8-12.

Kostiuk, S. (2018b). Psychological factors of intercultural competencies development of foreign students in the process of training the Ukrainian language. In M. Dey, \& O. Rudenko (Eds.), Association agreement: from partnership to cooperation (collective monograph), 232-236. Hamilton, Canada: Accent Graphics Communications \& Publishing.

Kyveryalg, A. A. (1980). Research methods in professional pedagogy. Tallinn, Estonia: Valgus.

Lalima \& Dangwal, K. L. (2017). Blended learning: An innovative approach. Universal Journal of Educational Research, 5(1), 129-136. https://doi.org/10.13189/ujer.2017.050116

Mebuke, T. (2016). Multicultural problems in language teaching. The International Virtual Forum: Humanitarian Aspect in Geocultural Space, 609-613. Istanbul, Turkey: Istanbul University.

Mesidor, J. K. \& Sly, K. F. (2016). Factors that contribute to the adjustment of international students. Journal of International Students, 6(1), 262-282.

Motsar, M. M. (2015). The use of media educational technologies in formation of multicultural competence of future translators. Ukrainian experience. International Review of Management and Marketing, 5(1S), 170-174.

Noble, A., Vangehuchten, L. \& Parys, W. V. (2011) Intercultural competence and effective communication at sea: An invitation to celebrate diversity on board. Proceedings of International Maritime English Conference IMEC-23, 131-149. Constanta, Romania: Editura NAUTICA.

Piller, I. (2017). Intercultural Communication: A Critical Introduction. Edinburgh, UK: Edinburg University Press.

Samovar, L. A., Porter, R. E., McDaniel, E. R. \& Sexton, R. C. (2010). Communication between Cultures: A Reader. 7th ed. Boston, MA: Wadsworth Publishing.

Slyusarenko, N. \& Soter, M. (2016). Formation of readiness of future marine engineers for intercultural communication using game simulation technology. Ukrainian Journal of Educational Research, 1(1), 53-57. 
https://doi.org/10.4324/9781315716282-11

Smelikova, V. B. (2015). Cases on Board Vessels. Kherson, Ukraine: KhSMA.

Smorochynska, O. (2011). Developing sociocultural competence as a key for improving cultural awareness of future seafarers. Proceedings of International Maritime English Conference IMEC-23, 120-130. Constanta, Romania: Editura NAUTICA.

Soter, M. (2016a). The role of cooperative learning in the formation of students' readiness to intercultural communication. Proceedings of International scientific-practical conference dedicated to the 25th anniversary of Independence of the Republic of Kazakhstan: Modern problems of the humanities and social sciences, 192-193. Astana, Republic of Kazakhstan: Eurasian Humanities Institute.

Soter, M. (2016b). Theoretical modelling of intercultural communication process. Journal of Advocacy, Research and Education, 6(2), 87-92.

Soter, M. (2017). Formation of the future marine engineers' readiness to intercultural communication as transcendental intercultural personalities. Proceedings of II International scientific conference: World Science in 2016: Results, 208-211. Morrisville, NC: Lulu Press.

Thome Williams, A. C. (2016). Developing intercultural communicative competence in Portuguese through Skype and Facebook. Journal of Intercultural Communication Studies, 25(1), 213-133.

Wang, Y., Li, T., Noltemeyer, A., Wang, A., Zhang, J. \& Shaw, K. (2018). Cross-cultural adaptation of international college students in the United States. Journal of international students, 8(2), 821-842. https://doi.org/10.32674/jis.v8i2.116 